Article

\title{
Enzyme Loading in Internally-Coated Capillary Tubes Via Kinetic Doping
}

\author{
Jessica M. Jensen $₫$ and Wai Tak Yip * \\ Department of Chemistry and Biochemistry, University of Oklahoma, Norman, OK 73071, USA; \\ jmjensen@ou.edu \\ * Correspondence: ivan-yip@ou.edu
}

Received: 10 April 2020; Accepted: 25 May 2020; Published: 30 May 2020

check for updates

\begin{abstract}
Development of capillary tubes internally doped with enzymes is of great interest for microfluidic reactions, and kinetic doping could provide a facile, inexpensive method for their manufacture. Kinetic doping has previously been demonstrated to have a high loading capacity with thin films coated on flat-surface coverslips. Dip coating of these surfaces was developed with the eventual intention to coat different shapes and sizes of substrates. In this study, we expanded the use of kinetic doping to internally-coated capillary tubes. Parameters for internally doping capillary tubes were developed with rhodamine 6G, which produced internally-coated thin films with a $90 \mathrm{~nm}$ thickness. Horseradish peroxidase (HRP) was then loaded into the capillary tubes, with a $47,000 \times$ increase in concentration over the loading solution. After excluding surface-adsorbed protein, the increase in HRP concentration in the thin films over the loading solution was determined to be $9850 \times$. The activity of the loaded HRP was determined to be $0.019 \pm 0.003 \mathrm{U} / \mathrm{mg}$ and shown to have a stronger resistance to denaturation by methanol.
\end{abstract}

Keywords: silica sol-gel; enzyme-doped; horseradish peroxidase; kinetic doping

\section{Introduction}

Many researchers have investigated the encapsulation of enzymes in silica in order to gain the benefits of immobilization, namely, high reusability and higher chemical and thermal stability [1-11]. Sol-gel-based technologies are especially promising, with their ease of synthesis and high loading capacity [9,12]. Silica sol-gel technology involves the gelation from a solution of silica alkoxides, at standard laboratory temperature and pressure, which creates a highly cross-linked thin film under acid-catalyzed conditions. Drain coating of silica sol-gel thin film does not require any specialized equipment. Devices containing sol-gel immobilized enzymes in silica could be inexpensively and easily fabricated for biosensing or catalysis purposes. Additionally, immobilized enzymes have shown resistance to and even catalytic activity in organic solvents $[13,14]$. This potential for microfluidic applications and catalysis in different solvents means immobilization of enzymes in silica has great potential.

Microfluidic and flow-through reactions catalyzed by immobilized enzymes have begun to receive increased attention from researchers in recent years [15-18], despite the loss of activity that generally comes from immobilization [19-21]. Flow-through reactions mainly rely on enzymes immobilized on beads [22,23], and much of the research in microfluidic devices is focused on 'lab on a chip' technologies, where a 'chip' or very small device is developed for specific microfluidic reactions [24-27]. However, there is also interest in devices based on glass capillary tubes [28,29] or another tubing that allows flow through reactions [30]. These types of devices can either rely on capillary action like many 'lab on a chip' technologies or have substrate driven through them by an external pump, providing a level of 
versatility in design. Of special interest, some of these devices are reconfigurable, allowing for multiple types of reactions to be performed with a single device, making them even more versatile [31].

The internal coating of capillary tubes does present certain challenges, however, leading to some authors using very involved methods to obtain a continuous film, like the manufacture of specialized equipment for the elevation-evacuation of sol within the capillary without vibrational disturbances [32], which may have led to less interest in internally-coated capillary tubes despite their many desirable traits. Chemical modification of the surfaces for immobilization of enzymes in devices is also commonly required [15-18], increasing the difficulty and expense of production. Overcoming these barriers to enable inexpensive and facile manufacturing of glass capillary tubes with high concentrations of immobilized enzymes could be of great benefit.

To that aim, we extended the kinetic doping technique developed by our group to internally coat capillary tubes with silica thin films with entrapped horseradish peroxidase (HRP). Kinetic doping is a doping method that utilizes a window of opportunity in the gelation process of silica thin films where the ethanol has been mostly driven off, but cross-linking has not significantly proceeded, where proteins can be entrapped by the film without being denatured by the ethanol solvent often used in silica sol-gel chemistry. This results in enzymes that are entrapped in the silica matrix through an economical and widely accessible technique. Kinetic doping has been shown to exhibit a high dopant capacity, produce films with good retention of enzyme activity, and nearly instantaneous response time [33]. This could lead to an inexpensive manufacturing process for enzyme-coated glass capillary tubes that is low on both material and labor cost, which is significant for potential commercialization. Additionally, this method could be extended to smaller diameter capillaries, leading to inexpensive microfluidic devices.

Here, we reported a facile, inexpensive method for entrapping horseradish peroxidase internally in silica thin films on glass capillary tubes using kinetic doping. The method was developed using a dye, rhodamine $6 \mathrm{G}(\mathrm{R} 6 \mathrm{G})$, and then applied to the enzyme horseradish peroxidase. The activity of the entrapped horseradish peroxidase in the capillary tubes was measured, and a method for measuring the quantity of entrapped enzyme was developed. Additionally, observations were made on the resistance of entrapped enzymes to normally denature ethanol and methanol. To our knowledge, this was the first time that an entrapped enzyme had been internally coated onto a capillary tube using the sol-gel method.

\section{Materials and Methods}

\subsection{Materials and General Methods}

Tetraethylorthosilicate (TEOS), rhodamine 6G (R6G), 95\% ethanol, and 99\% methanol were purchased from Sigma-Aldrich (St. Louis, MO, USA). Phosphoric acid and hydrogen peroxide ( $30 \%$ solution) were purchased from EMD Millipore (Burlington, Burlington, NJ, USA). Horseradish peroxidase (HRP) was purchased from Gold Biotechnology (St. Louis, MO, USA). Guaiacol was purchased from Cayman Chemical Company (Ann Arbor, USA). Glass capillary tubes ( $25 \mu \mathrm{L}$ Wiretrol Calibrated Micropipets) were made by Drummond (Broomall, PA, USA). Premium grade glass coverslips $(25 \mathrm{~mm} \times 25 \mathrm{~mm} \times 170 \mu \mathrm{m}$ ) were purchased from Fisher Scientific (Waltham, MA, USA) for use as glass substrates for thin-film coating. All chemicals and materials were used as received, with the exception of the glass capillary tubes and coverslips, which were cleaned prior to use. All UV-vis spectra were obtained via a Shimadzu UV-2101PC UV-vis spectrometer (Columbia, Portland, OR, USA). Scanning electron microscopy (SEM) images were obtained via a JEOL JSM-880 instrument (Peabody, MA, USA) with a $5 \mathrm{~nm}$ Au-Pd sputter-coated.

\subsection{Preparation of Glass Capillary Tubes}

To remove any organic contaminants on the capillary tube inner-surface, 95\% ethanol was pumped through each capillary for $5 \mathrm{~min}$. Deionized water was then pumped through each capillary for $5 \mathrm{~min}$. 
To remove aqueous contaminants, $10 \% \mathrm{HCl}$ was subsequently pumped through each tube for $5 \mathrm{~min}$. Finally, deionized water was then pumped through each capillary for $5 \mathrm{~min}$. The capillaries were stored in deionized water until use.

\subsection{Preparation of Silica Sol}

Silica sol was prepared by mixing a 1:8:7 molar ratio of TEOS:ethanol:water with phosphoric acid acting as a catalyst. A mixture of $55.9 \mathrm{~mL}$ of TEOS, $111.8 \mathrm{~mL}$ of ethanol, $31.7 \mathrm{~mL}$ of deionized water, and $0.62 \mathrm{~mL}$ of $1 \% v / v$ phosphoric acid at room temperature was prepared for most coatings. The sol was then allowed to age for $20 \mathrm{~h}$ at room temperature before use.

\subsection{Preparation of Internally-Doped Silica Sol-Gel Thin Films in Capillary Tubes}

Thin films were prepared by drain coating with a sol solution inside a centrifuge tube, based on the drain coated film preparation method of Crosley et al. [33]. After aging for $20 \mathrm{~h}$, the silica sol solution was transferred to a $50 \mathrm{~mL}$ round-bottom glass centrifuge tube, elevated by a jack stand. A clean capillary tube was purge dried with compressed air and immersed in the aged silica sol-gel coating solution while suspended from above. The capillary was positioned so that the sol was pulled up into the tube by capillary action to the $25 \mu \mathrm{L}$ mark. The sol solution in the centrifuge tube was then drained at a rate of $0.09 \mathrm{~cm} / \mathrm{s}$. The capillary was allowed to age on the drain coating set-up in ambient air for $5 \mathrm{~min}$, subsequently referred to as the delay time. It was then transferred to a hose with house air running through it at 3 liter per minute (LPM) for $1 \mathrm{~min}$, subsequently referred to as the drying time. The outside of the capillary was then wiped to remove any externally coated thin film. It was then placed in a test tube with a loading solution, where the loading solution was drawn into the tube through capillary action, again to the $25 \mu \mathrm{L}$ mark.

R6G was allowed to load into the film via kinetic doping for one hour, and HRP was allowed to load into the film for one week. The loading solution consisted of $1 \mathrm{mM}$ R6G in $10 \mathrm{mM}$ phosphate buffer, adjusted to $\mathrm{pH} 7.4$ with phosphoric acid or $0.1 \mathrm{mg} / \mathrm{mL}$ HRP in $10 \mathrm{mM}$ phosphate buffer, adjusted to $\mathrm{pH} 7.4$ with phosphoric acid. After loading, capillaries were removed from the solution, rinsed with deionized (DI) water to remove all of the adsorbed R6G or most of the adsorbed HRP, dried with house air, and tested or stored for future use. Post-doped controls, where HRP is immobilized via simple surface adsorption, were made by extending the delay time to $15 \mathrm{~min}$ and the dry time to $10 \mathrm{~min}$ and then submerging the tubes in $10 \mathrm{mM}$ phosphate buffer, $\mathrm{pH}$ 7.4, for one hour. The capillaries were then removed, rinsed, and dried and placed in the same loading solution for the same amount of time as the kinetically doped samples for comparison.

Flat surface films were prepared using the same methods, but omitting the purge-drying step. Flat coverslips $(25 \mathrm{~mm} \times 25 \mathrm{~mm} \times 170 \mu \mathrm{m})$ were suspended above a beaker atop a jack stand containing the sol solution, and the jack stand was raised until the coverslip was completely submerged. The sol was drained at the same rate, and coverslips were placed directly in loading solutions after a $5 \mathrm{~min}$ delay time [34].

All thin film morphology and thickness measurements inside capillary tubes and on flat surfaces were obtained from SEM images recorded by a JEOL JSM-880 instrument.

\subsection{Quantitative Determination of HRP Loading}

Initially, attempts were made to quantify HRP loading in capillary tubes with the modified Bradford Assay developed by Crosley et al [8]. Briefly, Coomassie Brilliant Blue was pumped into capillaries and allowed to equilibrate. The solution was then pumped into a cuvette, and the decrease in the unbound form of the dye was measured with UV-vis absorption. These results exhibited poor correlation and could not be used to quantify loaded HRP reliably.

HRP loading in capillary tubes was quantified via the ninhydrin method of protein quantification based on the procedure developed by Troll et al. [35]. Briefly, solutions of $500 \mathrm{mg}$ of ninhydrin dissolved in $10 \mathrm{~mL}$ of absolute ethanol, $80 \mathrm{mg}$ of phenol dissolved in $20 \mathrm{~mL}$ absolute ethanol, and $2 \mathrm{~mL}$ of $0.01 \mathrm{M}$ 
$\mathrm{KCN}$ in $100 \mathrm{~mL}$ pyridine were prepared. Capillary tubes that had been loaded with HRP were allowed to sit in $2 \mathrm{~mL}$ of $2 \mathrm{M} \mathrm{NaOH}$ for two weeks to dissolve the thin film and release the encapsulated HRP, and then the solution was brought to approximately $\mathrm{pH} 7$ with concentrated $\mathrm{HCl}$. One milliliter of this solution was then combined with $2 \mathrm{~mL}$ of the phenol and $2 \mathrm{~mL}$ of the KCN solutions in a test tube. The test tube was then stoppered and placed into a boiling water bath and allowed to equilibrate. The $0.4 \mathrm{~mL}$ of the ninhydrin solution was then added, and the reaction was allowed to proceed for $5 \mathrm{~min}$. The reaction of the test reagents and any primary or secondary amines in the denatured protein produces the dye Ruhemann's purple, a dye which absorbs at $571 \mathrm{~nm}$. The absorbance of this solution was then measured. A standard curve was constructed by dissolving known quantities of $\mathrm{HRP}$ in $2 \mathrm{M} \mathrm{NaOH}$ and following the same procedure (this calibration curve can be found in the supplemental materials as Figure S1). The samples were compared to the standard curve to determine the amount of HRP in solution, and the original amount of HRP in the capillary tubes was then calculated. The absorbance of the sample solutions did not increase when the capillary tubes were allowed to sit in $\mathrm{NaOH}$ for more than two weeks, so all HRP was assumed to be released into solution in two weeks.

\subsection{Quantitative Determination of HRP Activity}

The activity of the entrapped HRP was assessed through an HRP/guaiacol assay. The formation of the quinone product was monitored through UV-vis absorption at $436 \mathrm{~nm}$. A $100 \mathrm{~mL}$ solution of $3.3 \mu \mathrm{L}$ liquid guaiacol and $1.4 \mu \mathrm{L} 30 \%$ hydrogen peroxide in $\mathrm{pH} 7.410 \mathrm{mM}$ phosphate buffer was pumped into capillary tubes for differing time periods and then pumped back into a cuvette for absorption measurement. Due to adsorbed HRP washing off of the tubes and continuing to react in the cuvettes, the formation of the quinone was monitored for several minutes, and the concentration at the time the solution was pumped out of the capillaries was obtained by extrapolation (an example of one of these graphs can be found in the supplemental materials as Figure S2). The enzyme activity could then be calculated using the initial rate method as all measured time points fell into the initial linear rate portion of the reaction (the activity determination curve can be found in the supplemental materials as Figure S3).

\section{Results and Discussion}

\subsection{Parameter Optimization with Rhodamine 6G}

Internally coating a capillary tube with a silica thin film using the sol-gel method presented unique challenges as compared to flat surface coating. The sol-gel process worked through two main reactions: hydrolysis and polycondensation. These reactions released ethanol and water into the surrounding air as the film gels. The formation of the films required the evaporation of these by-products. The enclosure inherent in capillary tubes impeded this evaporation, slowing the formation of the films. Additionally, exposure to the sol vapors is known to negatively affect flat surface films, damaging the structural integrity of the film [33]. Instead of a continuous film, exposure to vapors resulted in sparse aggregates. This could be seen by the loading of R6G, which only loaded into the coated silica aggregates (as shown by the faint, mottled loading in Figure 1A) and did not adhere to the glass substrate after washing.

To prevent this, house air was forced through the capillary tubes after drain coating. Initially, capillary tubes were drained of sol and then put immediately onto a hose with an attached air regulator. This resulted in films that were, to the eye, evenly coated with R6G (see Figure 2A). However, as SEM images revealed, the sol had formed aggregates, instead of films, on the inside of the capillary tubes (see Figure 2B). This was likely due to vibrations introduced when moving the capillary from the drain coating set-up to the purge drying set-up. The vibrations disrupted the film development and compromised its structural integrity before there was sufficient polycondensation to set the film, thereby breaking the nascent film into aggregates. 


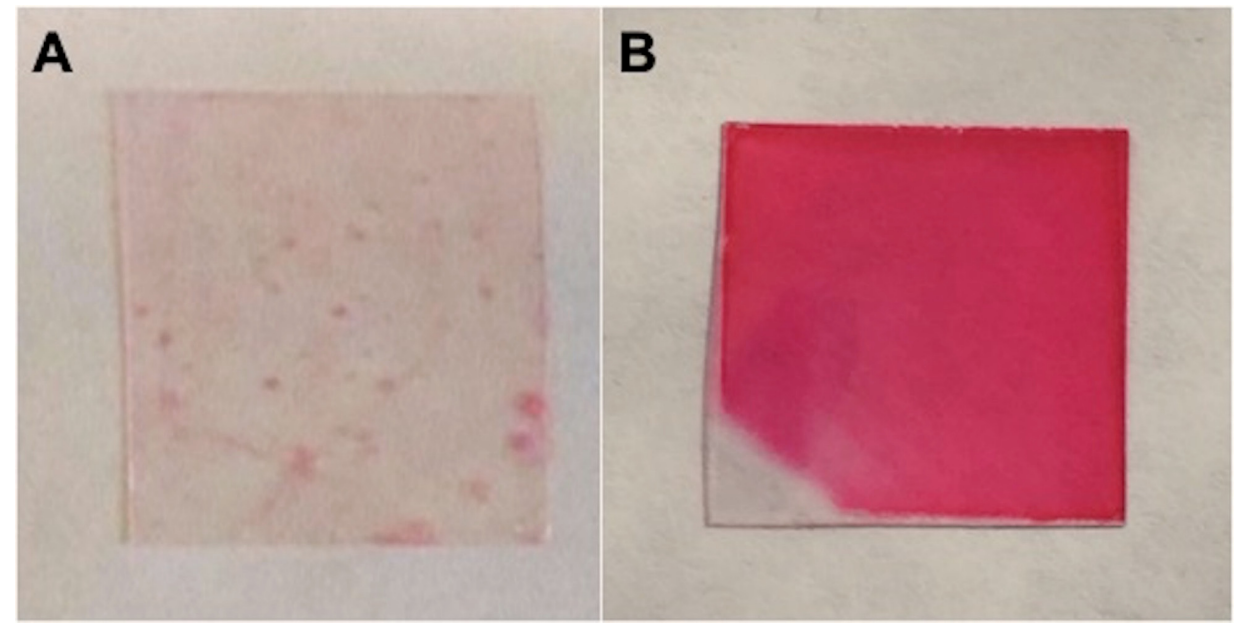

Figure 1. (A) Photograph of film that was exposed to the vapors from the sol while aging. Sparse aggregates loaded with rhodamine 6G (R6G) could be seen on the film. (B) Photograph of film that was not exposed to vapors while aging. The continuous film loaded with R6G, except the corner that was not dipped into the sol during coating, could be seen.

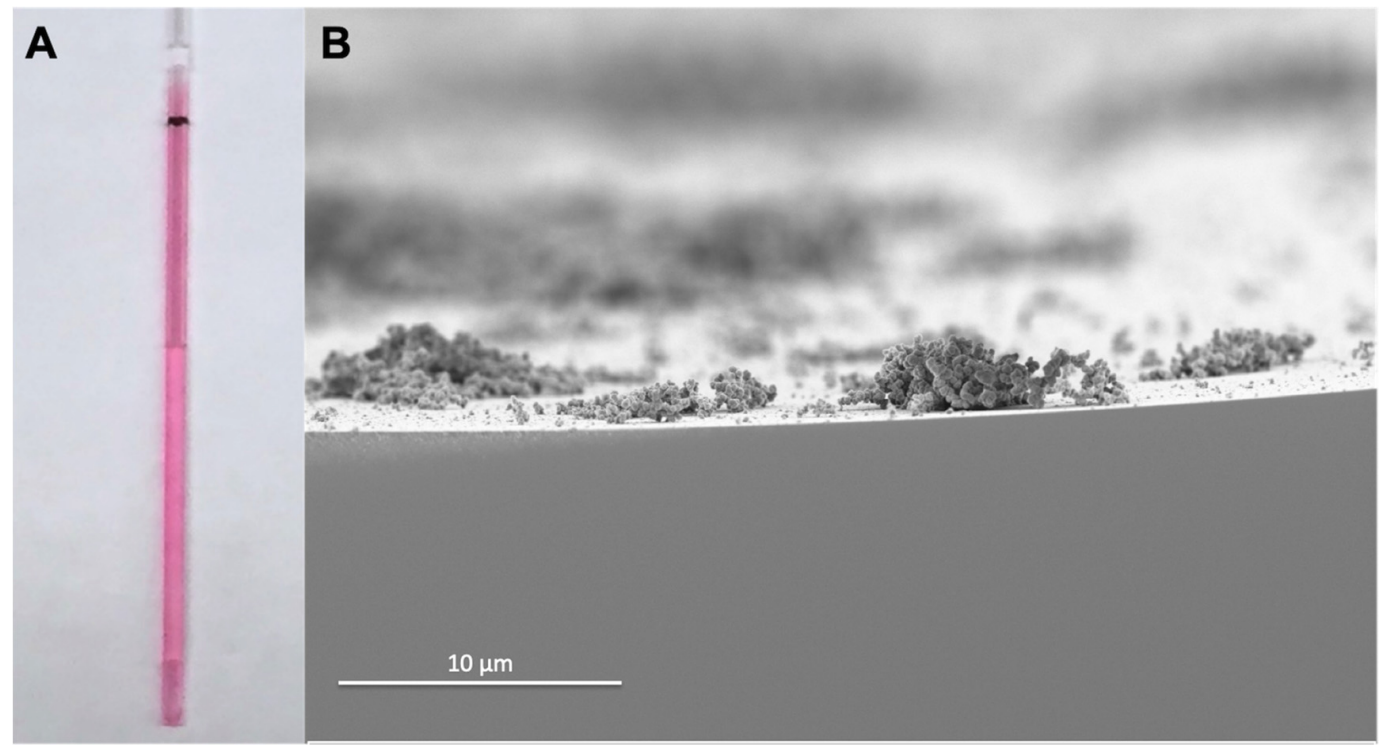

Figure 2. (A) Photograph of the capillary tube with no delay time and $1 \mathrm{~min}$ drying time at 3 liter per minute (LPM) airflow, loaded with R6G. (B) SEM of a capillary tube at 3000×, made using the same parameters, showing aggregates instead of a thin film.

Drying time is also necessary; however, as films that had a 5 min delay time but were not purge dried did not show loading (see Figure 3A). Drying times of 1, 2, 5, and $10 \mathrm{~min}$ (see Figure 3B-E) were tested for loading. One minute of purge drying at 3 LPM was enough to enable loading, as the minimum amount of drying time should lead to higher kinetic doping. Several delay times from $5 \mathrm{~min}$ to $15 \mathrm{~min}$ were tested with a $1 \mathrm{~min}$ drying time at 3 LPM after all delay times. While the capillary tubes looked visually similar to the capillaries without delay time, the SEM images showed a thin film instead of aggregates (see Figure 4). While these films were not even, and some aggregates could still be seen attached to the film surface, they were consistent for all delay times. Several measurements of film thickness were taken ( $n=12,3$ measurements each of 4 films), resulting in average thickness measurement of $90 \mathrm{~nm}$. Thus, a delay time of $5 \mathrm{~min}$, the shortest delay time needed to achieve a film, 
was chosen for further coating. With parameters for an intact film determined, subsequent loading was done with horseradish peroxidase.
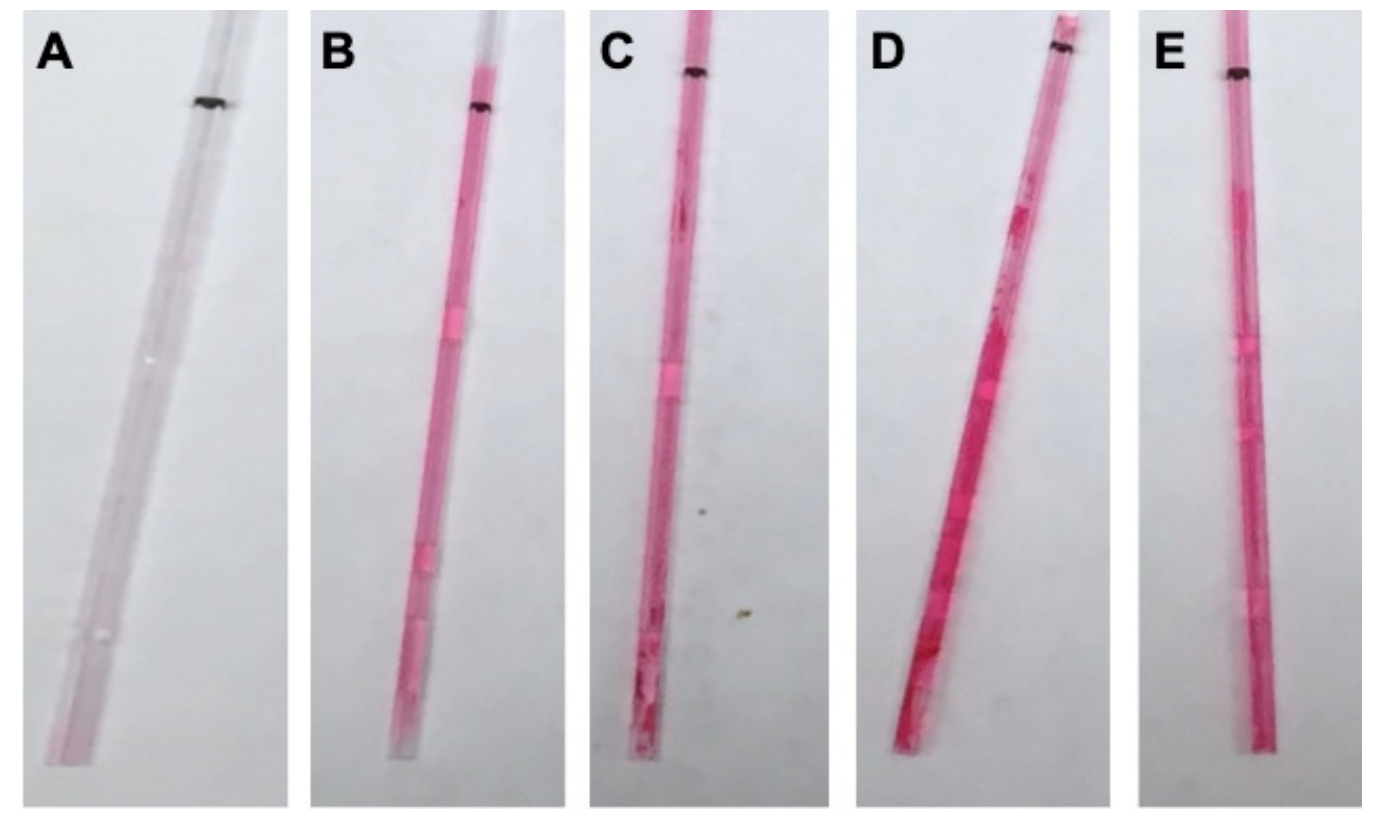

Figure 3. Capillary tubes loaded with R6G with a delay time of $5 \mathrm{~min}$, dried at 3 LPM for (A) 0 min, (B) 1 min, (C) 2 min, (D) 5 min, (E) $10 \mathrm{~min}$.

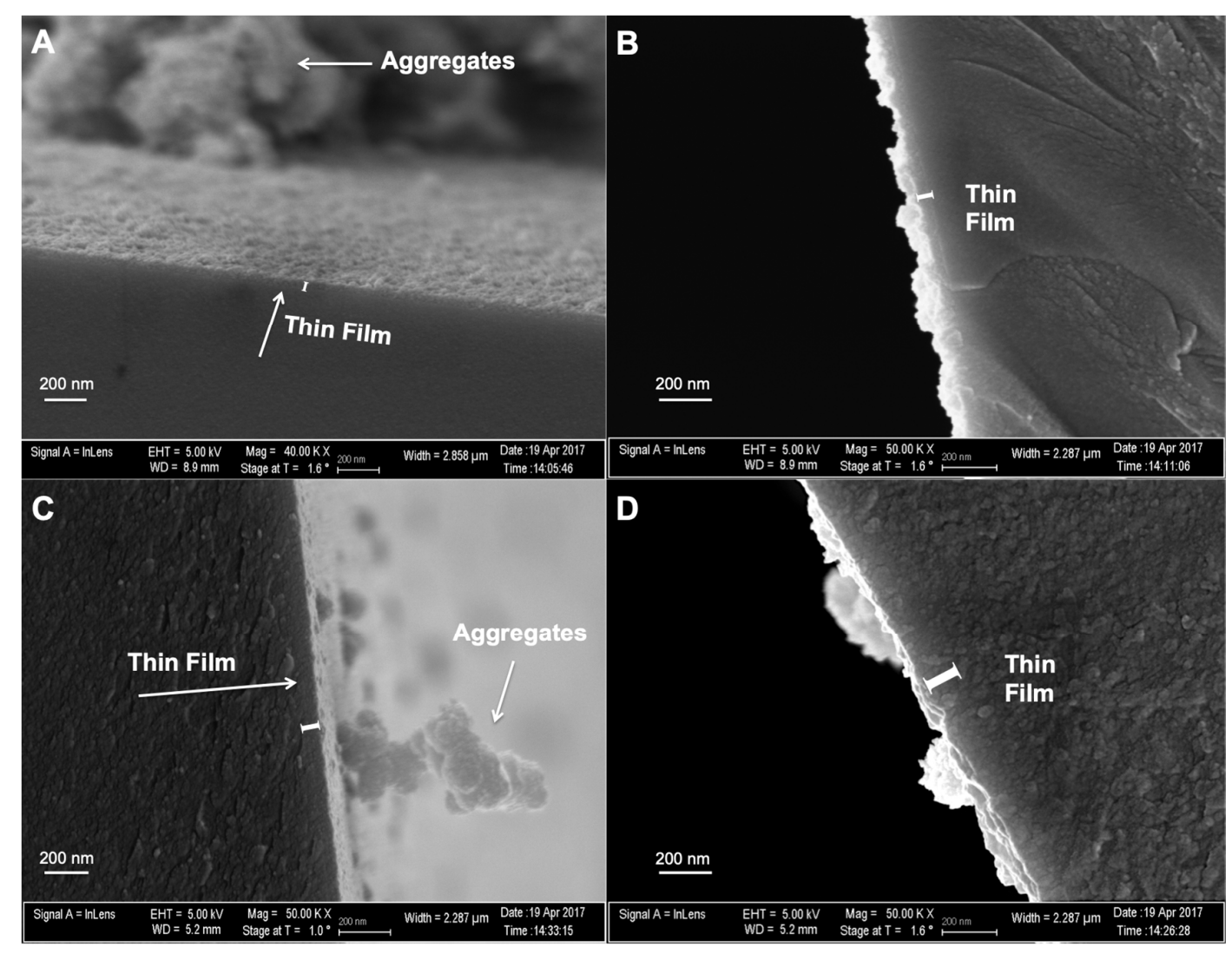

Figure 4. SEM images of capillary tubes loaded with R6G, with a dry time of 1 min and a delay time of (A,B) $5 \mathrm{~min}$ and (C,D) $15 \mathrm{~min}$. Both films were approximately $90 \mathrm{~nm}$ thick, although the thickness of the film was highly variable for both delay times. 


\subsection{Quantitative Determination of Horseradish Peroxidase Loading}

Using the parameters determined from R6G loading, horseradish peroxidase (HRP) was loaded into the capillary tubes. After loading, the same guaiacol assay that was used for flat-surface films was used to check for enzyme activity, but an assay had to be developed to quantify the amount of protein loaded into the capillaries first.

The internally-coated thin films were dissolved by incubating the tubes with $2 \mathrm{M}$ sodium hydroxide for two weeks. A ninhydrin assay was then performed on the dissolved films, which was compared to a standard curve made from free HRP denatured in $2 \mathrm{M}$ sodium hydroxide. Using this curve, the capillary tubes were determined to have an average of $0.051 \pm 0.007 \mathrm{mg}$ of the protein loaded. Using the $90 \mathrm{~nm}$ average thickness, a concentration of approximately $0.11 \mathrm{M}$ or $4700 \mathrm{mg} / \mathrm{mL}$-a $47,000 \times$ increase from the loading solution-was calculated. It is worth noting that $4700 \mathrm{mg} / \mathrm{mL}$ exceeded even the typical density of solid protein of $1300-1500 \mathrm{mg} / \mathrm{mL}$ [36]. The most likely explanation is that the capillary tubes also had a large amount of adsorbed HRP on the internal surface, which could not be easily washed off. The exact amount of HRP trapped inside the thin film was expected to be lower. A post-doped control that contributes mostly by surface HRP adsorption showed a loading of $3700 \mathrm{mg} / \mathrm{mL}$, which was $79 \%$ of the total loading. Kinetic doping would thus account for $985 \mathrm{mg} / \mathrm{mL}$ of HRP loaded into the film, a 9850x increase over the initial loading solution.

This was an even larger increase over the initial loading solution than seen with flat surface loading, which had an increase of 2400x; it is worth noting, however, the modified Bradford assay used on flat surface loading was only able to quantify the solvent-accessible HRP and was thought to underestimate the amount of total HRP loaded due to the size of the Coomassie blue dye limiting its diffusion into the thin film [33]. The modified Bradford assay developed by Crosley et al. [8] to quantify the amount of HRP loaded onto flat-surface coverslips could not be used for capillary tubes. The results obtained from such measurements in the capillary tube exhibited poor correlation for both the decrease of the unbound form or the increase of the bound form of the Coomassie blue dye and thus deemed unreliable for this work. The ninhydrin assay here worked with the dissolved thin film, so all loaded protein, not just the solvent-accessible protein, was quantified.

The HRP that was kinetically doped did differ from the post-doped HRP, as demonstrated by denaturation of the protein with ethanol and methanol. Both kinetically doped and post-doped capillaries showed activity after soaking in 30\% ethanol for one week or after pumping $95 \%$ ethanol through the capillaries for $48 \mathrm{~h}$. This exposure to ethanol would denature free HRP in solution. Additionally, kinetically doped capillaries kept activity when $99 \%$ methanol was pumped through the tubes for $15 \mathrm{~s}$, but the methanol stopped the activity of the post-doped controls. Pumping 99\% methanol through either the kinetically doped or post-doped capillaries for longer than $15 \mathrm{~s}$ deactivated all HRP. Images of these tubes, with kinetically doped tubes that were and were not exposed to methanol and a post-doped control that has been exposed to methanol, are seen in Figure 5. This resistance seemed to mean that both types of doping provided a large degree of protection from ethanol, which is not uncommon for enzymes trapped in solid state [37]. However, the kinetically doped HRP afforded additional protection from even methanol. The additional protection provided by kinetic doping over post-doped controls meant that kinetically doped internally-coated capillary tubes had the potential to utilize enzymes to catalyze reactions in non-aqueous solutions or to be sterilized for possible medical applications more than a traditional method of entrapping proteins on a flat surface as they are more resistant to denaturing solvents. 


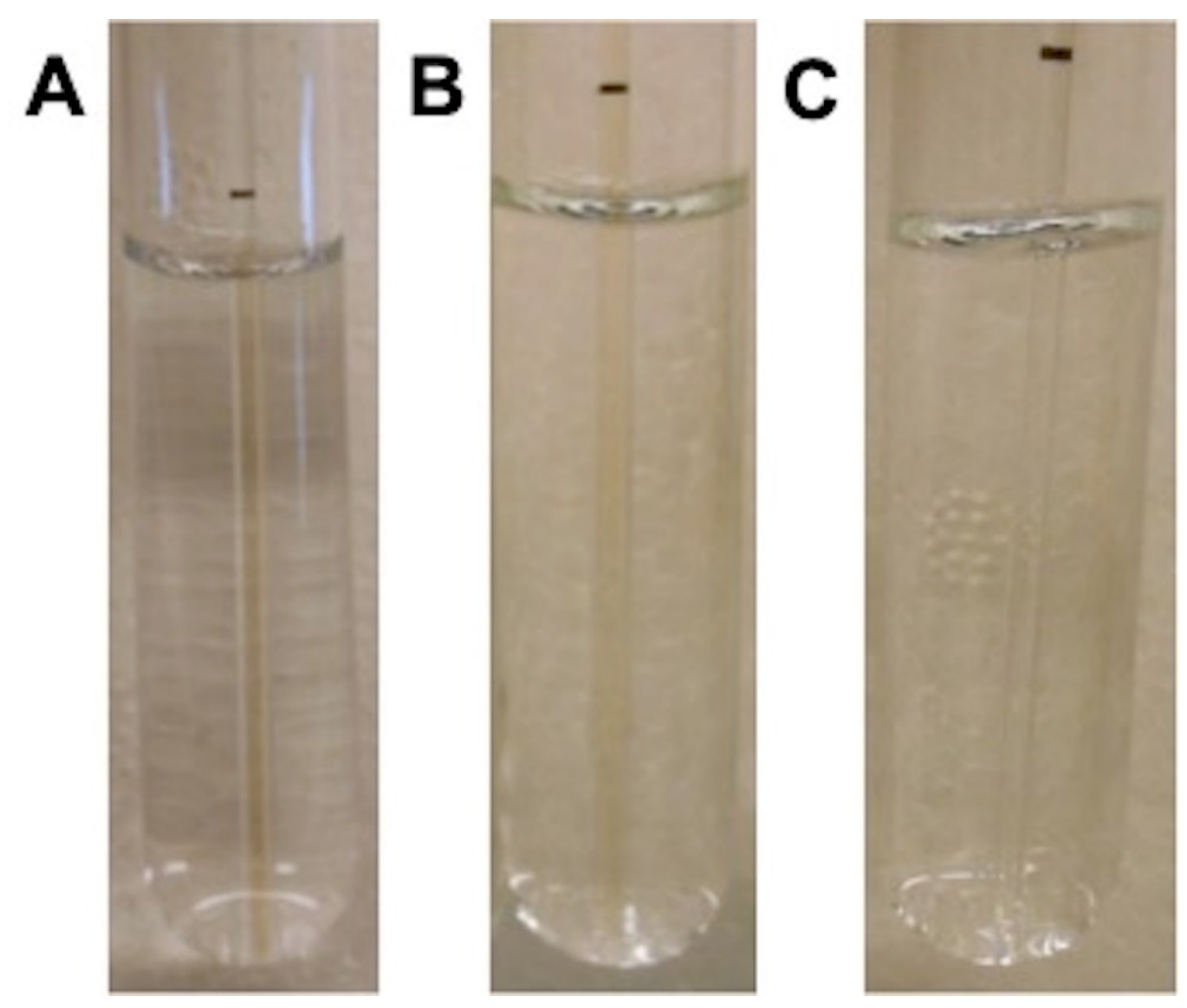

Figure 5. (A) Capillary tube kinetically doped with HRP exposed to the guaiacol/hydrogen peroxide assay, showing the dark brown quinone product. This product indicated the enzymes were still active after loading. (B) Capillary tube kinetically doped with HRP exposed to the guaiacol/hydrogen peroxide assay after being exposed to methanol for $15 \mathrm{~s}$, still showing the dark brown quinone product. This product indicated the enzymes were still active after methanol exposure. (C) Capillary tube post-doped with HRP exposed to the guaiacol/hydrogen peroxide assay after being exposed to methanol for $15 \mathrm{~s}$, with the dark brown quinone product no longer being produced. The lack of this product indicated the enzymes were no longer active.

\subsection{Activity Determination of Horseradish Peroxidase}

After the determination of the amount of HRP loaded into the thin films, the activity of the enzyme had to be determined to assess the application potential of the internally-coated capillary tubes. The ability of the enzyme to catalyze guaiacol was quantified through monitoring the appearance of the quinone product by UV-vis spectroscopy in a series of time points. Using the activity and the amount of HRP loaded into the capillary tube, the activity per milligram of protein was calculated to be $0.019 \pm 0.003 \mathrm{U} / \mathrm{mg}$. This was a marked decrease from the activity of free HRP, $35.4 \pm 0.8 \mathrm{U} / \mathrm{mg}$, or HRP loaded onto a flat-surface substrate, $3.7 \pm 0.2 \mathrm{U} / \mathrm{mg}$ [33].

The low activity might be partially explained by the method of protein quantification used here versus the modified Bradford assay used to quantify the loading in flat surface samples. In this work, all protein, even that which was not accessible to the solution, was quantified by dissolving the film. Only solvent-accessible HRP was quantified by the Bradford assay, which was the only HRP that could interact with the substrate. Any HRP that is not solvent accessible would artificially deflate the activity of the capillary tubes. The increase in concentration over the loading solution was $410 \%$ higher in the capillary tubes than on a flat surface, but it seemed unlikely such a similar doping protocol would yield such different results. More likely, much of the protein quantified in the capillary thin films was not solvent accessible, increasing the amount quantified but not the amount available to interact with the substrate. Moreover, the surface area of a capillary tube was approximately $95 \%$ less than that of the flat surface samples. If more HRP was loaded into the film in capillary tubes, then it would, by necessity, be solvent-inaccessible due to the decreased surface area. Given the decrease in surface 
area and the marked increase in HRP concentration in the film, the decrease in activity was likely not due to any additional denaturing or restriction of the enzyme in the capillaries versus the coverslips, but due to the solvent-inaccessibility of the majority of the enzymes.

To test this hypothesis, the amount of entrapped yet solvent-accessible R6G dye between the capillary tubes and flat surface films was compared. R6G loading in capillary tubes and flat surface films was determined by ethanol extraction. Capillary tubes loaded with R6G were submerged in 95\% ethanol for $24 \mathrm{~h}$, to allow all trapped dye to escape into solution. Briefly, each of the capillaries was placed into glass test tubes, and ethanol was added until capillary action brought it in contact with all loaded portions of the film. The capillary tubes were manually agitated periodically. No visible traces of R6G remained after $24 \mathrm{~h}$, and no increase in absorbance was observed at extraction time beyond $24 \mathrm{~h}$. For comparison, flat surface films were submerged in $95 \%$ ethanol for multiple days by placing each loaded film in a separate beaker and adding ethanol until films were completely covered. The films were sonicated, and the solvent was replaced three times with fresh $95 \%$ ethanol, in an attempt to extract all solvent accessible dye from the silica film. Flat surface films had visible traces of permanently trapped R6G remaining, but no increase in absorbance of the extracted solution was observed with further extraction. The absorbance of these solutions was then measured at $532 \mathrm{~nm}$-the maximum absorbance wavelength of R6G in ethanol. The thickness of the flat surface films was calculated using the Landau-Levich equation [38] to determine the original R6G concentration in the films. It was found that internally-coated capillary tubes had a solvent-accessible R6G concentration of $0.58 \pm 0.04 \mathrm{M}$, while flat surface films, with the same loading parameters and using the same quantification method, had a concentration of $1.0 \pm 0.2 \mathrm{M}$-almost double the amount in the capillaries. The higher loading of dye in the flat surface films over the internally-coated capillary tubes suggested the amount of HRP loaded would also likely be higher in the flat surface films if the same quantification method could be used.

Additionally, the measured activity of the HRP in the capillary tubes, even with the likely underestimation, was still comparable to that achieved in covalently bonded HRP in packed bed columns [23]. This means that flow-through reactions could be carried out with approximately the same efficiency in the internally-coated capillaries, but with much smaller amounts of substrate and solvent.

\section{Conclusions}

In this study, we demonstrated the ability to kinetically dope internally-coated capillary tubes with silica thin films by the sol-gel method. This method was less complex than previous methods used to internally coat capillary tubes by the sol-gel method and had a high enzyme loading capacity, resulting in a 47,000× increase in HRP concentration in the capillary tube over the loading solution. After eliminating contribution from surface adsorption, the increase in HRP concentration in thin films reduced to $9850 \times$. While the activity of the enzyme was markedly decreased by entrapment, its resistance to denaturing methanol was increased compared to post-doped controls. This was the first time, to our knowledge, that enzymes had been loaded into internally-coated thin films using the sol-gel method. The method to load these internally-coated capillary tubes developed here represented a step toward the facile and inexpensive development of reconfigurable devices that could be used to enable complex reaction schemes in microfluidic devices.

Supplementary Materials: The following are available online at http://www.mdpi.com/2079-6412/10/6/532/s1, Figure S1: Ninhydrin HRP Calibration Curve, Figure S2: Guaiacol Product vs. Time, Figure S3: Sample of HRP Activity Extrapolation.

Author Contributions: Conceptualization, W.T.Y. and J.M.J.; methodology, J.M.J.; investigation, J.M.J.; resources, W.T.Y.; writing —original draft preparation, J.M.J.; writing—review and editing, J.M.J. and W.T.Y.; supervision, W.T.Y. All authors have read and agreed to the published version of the manuscript.

Funding: This research received no external funding.

Acknowledgments: The authors would like to thank Preston Larson for collecting the SEM images.

Conflicts of Interest: The authors declare no conflict of interest. 


\section{References}

1. Ryu, Y.H.; Yeo, K.B.; Ki, M.-R.; Kim, Y.J.; Pack, S.P. Improved stability and reusability of endoglucanase from Clostridium thermocellum by a biosilica-based auto-encapsulation method. Biochem. Eng. J. 2016, 105, 144-149. [CrossRef]

2. Ellerby, L.M.; Nishida, C.R.; Nishida, F.; Yamanaka, S.A.; Dunn, B.; Valentine, J.S.; Zink, J.I. Encapsulation of proteins in transparent porous silicate glasses prepared by the sol-gel method. Science 1992, 255, 1113-1115. [CrossRef] [PubMed]

3. Braun, S.; Rappoport, S.; Zusman, R.; Avnir, D.; Ottolenghi, M. Biochemically active sol-gel glasses: The trapping of enzymes. Mater. Lett. 1990, 10,1-5. [CrossRef]

4. Gill, I.; Ballesteros, A. Encapsulation of biologicals within silicate, siloxane, and hybrid sol-gel polymers: An efficient and generic approach. J. Am. Chem. Soc. 1998, 120, 8587-8598. [CrossRef]

5. Gill, I.; Ballesteros, A. Bioencapsulation within synthetic polymers (Part 1): Sol-gel encapsulated biologicals. Trends Biotechnol. 2000, 18, 282-296. [CrossRef]

6. Bhatia, R.B.; Brinker, C.J.; Gupta, A.K.; Singh, A.K. Aqueous sol-gel process for protein encapsulation. Chem. Mater. 2000, 12, 2434-2441. [CrossRef]

7. Pierre, A.C. The sol-gel encapsulation of enzymes. Biocatal. Biotransformation 2004, 22, 145-170. [CrossRef]

8. Crosley, M.S.; Yip, W.T. Silica sol-gel optical biosensors: Ultrahigh enzyme loading capacity on thin films via kinetic doping. J. Phys. Chem. B 2017, 121, 2121-2126. [CrossRef]

9. Jeronimo, P.C.A.; Araujo, A.N.; Montenegro, M.C.B.S.M. Optical sensors and biosensors based on sol-gel films. Talanta 2007, 72, 13-27. [CrossRef]

10. Ciriminna, R.; Fidalgo, A.; Pandarus, V.; Beland, F.; Ilharco, L.M.; Pagliaro, M. The sol-gel route to advanced silica-based materials and recent applications. Chem. Rev. 2013, 113, 6592-6620. [CrossRef]

11. Zhang, F.; Wang, M.; Liang, C.; Jiang, H.; Shen, J.; Li, H. Thin-layer polymer wrapped enzymes encapsulated in hierarchically mesoporous silica with high activity and enhanced stability. Sci. Rep. 2014, 4. [CrossRef] [PubMed]

12. Crosley, M.S.; Yip, W.T. Multienzyme, multistep biosensor produced through kinetic doping. J. Phys. Chem. B 2019, 123, 3962-3967. [CrossRef] [PubMed]

13. Takahashi, H.; Li, B.; Sasaki, T.; Miyazaki, C.; Kajino, T.; Inagaki, S. Catalytic activity in organic solvents and stability of immobilized enzymes depend on the pore size and surface characteristics of mesoporous silica. Chem. Mater. 2000, 12, 3301-3305. [CrossRef]

14. Takahashi, H.; Li, B.; Sasaki, T.; Miyazaki, C.; Kajino, T.; Inagaki, S. Immobilized enzymes in ordered mesoporous silica materials and improvement of their stability and catalytic activity in an organic solvent. Microporous Mesoporous Mater. 2001, 44-45, 755-762. [CrossRef]

15. Lian, X.; Fang, Y.; Joseph, E.; Wang, Q.; Li, J.; Banerjee, S.; Lollar, C.; Wang, X.; Zhou, H.-C. Enzyme-MOF (metal-organic framework) composites. Chem. Soc. Rev. 2017, 46, 3386-3401. [CrossRef] [PubMed]

16. Zhu, Y.; Chen, Q.; Shao, L.; Jia, Y.; Zhang, X. Microfluidic immobilized enzyme reactors for continuous biocatalysis. React. Chem. Eng. 2020, 5, 9-32. [CrossRef]

17. Honda, T.; Yamaguchi, H.; Miyazaki, M. Development of enzymatic reactions in miniaturized reactors. Adv. Biotechnol. 2017, 5, 99-166. [CrossRef]

18. Britton, J.; Majumdar, S.; Weiss, G.A. Continuous flow biocatalysis. Chem. Soc. Rev. 2018, 47, 5891-5918. [CrossRef]

19. Monton, M.R.N.; Forsberg, E.M.; Brennan, J.D. Tailoring sol-gel-derived silica materials for optical biosensing. Chem. Mater. 2012, 24, 796-811. [CrossRef]

20. Heller, J.; Heller, A. Loss of activity or gain in stability of oxidases upon their immobilization in hydrated silica: Significance of the electrostatic interactions of surface arginine residues at the entrances of the reaction channels. J. Am. Chem. Soc. 1998, 120, 4586-4590. [CrossRef]

21. Zoungrana, T.; Findenegg, G.H.; Norde, W. Structure, stability, and activity of adsorbed enzymes. J. Colloid Interface Sci. 1997, 190, 437-448. [CrossRef] [PubMed]

22. Heinzler, R.; Fischoeder, T.; Elling, L.; Franzreb, M. Toward automated enzymatic glycan synthesis in a compartmented flow microreactor system. Adv. Synth. Catal. 2019, 361, 4506-4516. [CrossRef] 
23. Bilal, M.; Iqbal, H.M.N.; Hussain Shah, S.Z.; Hu, H.; Wang, W.; Zhang, X. Horseradish peroxidase-assisted approach to decolorize and detoxify dye pollutants in a packed bed bioreactor. J. Environ. Manag. 2016, 183, 836-842. [CrossRef] [PubMed]

24. Liao, Z.; Wang, J.; Zhang, P.; Zhang, Y.; Miao, Y.; Gao, S.; Deng, Y.; Geng, L. Recent advances in microfluidic chip integrated electronic biosensors for multiplexed detection. Biosens. Bioelectron. 2018, 121, 272-280. [CrossRef]

25. Zhou, W.; Le, J.; Chen, Y.; Cai, Y.; Hong, Z.; Chai, Y. Recent advances in microfluidic devices for bacteria and fungus research. Trends Anal. Chem. 2019, 112, 175-195. [CrossRef]

26. Mukherji, S.; Mondal, D. Lab-on-chip (LOC) devices for point of care (POC) applications. Woodhead Publ. Ser. Biomater. 2017, 118, 99-131. [CrossRef]

27. Li, N.; Zhang, W.; Li, Y.; Lin, J.-M. Analysis of cellular biomolecules and behaviors using microfluidic chip and fluorescence method. Trends Anal. Chem. 2019, 117, 200-214. [CrossRef]

28. Tan, X.; Khaing Oo, M.K.; Gong, Y.; Li, Y.; Zhu, H.; Fan, X. Glass capillary based microfluidic ELISA for rapid diagnostics. Analyst 2017, 142, 2378-2385. [CrossRef]

29. Besanger, T.R.; Hodgson, R.J.; Green, J.R.A.; Brennan, J.D. Immobilized enzyme reactor chromatography: Optimization of protein retention and enzyme activity in monolithic silica stationary phases. Anal. Chim. Acta 2006, 564, 106-115. [CrossRef]

30. Jannat, M.; Yang, K.-L. Immobilization of enzymes on flexible tubing surfaces for continuous bioassays. Langmuir 2018, 34, 14226-14233. [CrossRef]

31. Bandulasena, M.V.; Vladisavljevic, G.T.; Benyahia, B. Versatile reconfigurable glass capillary microfluidic devices with Lego inspired blocks for drop generation and micromixing. J. Colloid Interface Sci. 2019, 542, 23-32. [CrossRef] [PubMed]

32. Jing, C.; Zhao, X.; Han, J.; Zhu, K.; Liu, A.; Tao, H. A new method of fabricating internally sol-gel coated capillary tubes. Surf. Coat. Technol. 2003, 162, 228-233. [CrossRef]

33. Crosley, M.S.; Yip, W.T. Kinetically doped silica sol-gel optical biosensors: expanding potential through dip-coating. ACS Omega 2018, 3, 7971-7978. [CrossRef] [PubMed]

34. Jensen, J.M.; Yip, W.T. Amine Functionalization of silica sol-gel thin films via kinetic doping: A novel, green approach. ACS Omega 2019, 4, 18545-18554. [CrossRef]

35. Troll, W.; Cannan, R.K. A modified photometric ninhydrin method for the analysis of amino and imino acids. J. Biol. Chem. 1953, 200, 803-811.

36. Fischer, H.; Polikarpov, I.; Craievich, A.F. Average protein density is a molecular-weight-dependent function. Protein Sci. 2004, 13, 2825-2828. [CrossRef]

37. Kunkel, J.; Asuri, P. Function, structure, and stability of enzymes confined in agarose gels. PLoS ONE 2014, 9, e86785. [CrossRef]

38. Landau, L.; Levich, B. Dragging of a liquid by a moving plate. Acta Physicochim. URSS 1942, 17, 42-54. 